\title{
Using Reflexive Agency to Explore Students' Access to Online Learning Resources in Resource Constrained Learning Environments
}

\author{
Patient Rambe \\ Department of Business Support Services, Central University of Technology, \\ Private Bag 20539 ,Bloemfontein 9300, South Africa \\ Email: prambe2000@yahoo.com \\ Delson Chikobvu \\ Department of Mathematical Statistics and Actuarial Sciences, University of Free State, \\ P.O. Box 339 Bloemfontein 9300, South Africa \\ Email: chikobvu@ufs.ac.za
}

\section{Doi:10.5901/mjss.2014.v5n20p1147}

\begin{abstract}
The discourse on student access to learning resources in resource-poor African environments is often steeped in the digital divide, which reinforces technological determinism. However, at historically privileged South African universities where institutionally-sanctioned networks and learning environments mediate universal on-campus access to technologies, the digital divide insufficiently accounts for variations in student access to networked resources. The persistent information asymmetries cannot be explained diametrically in terms of digital natives and digital stranger arguments. This paper employs Archer's construction of agency as an interpretive lens for understanding how students in resource-poor contexts appropriate existing technologies, enact new practices and renegotiate access to deal with inequitable technology provision. Findings suggest that albeit strategic but complex choices that students make regarding access to educational resources, historically-induced cultural imbalances, socio-economic disadvantage and gender asymmetries continue to implicate student access to these resources. Students tended to switch strategically to mobile access when access to resources via walk-in labs proved to be a challenge. Moreover, student levels of study and gender played a moderating role in their access to educational technologies. The study recommends context-driven, social practice informed approaches to the deployment of technologies in resource-constrained environments to address challenges of accessing educational resources.
\end{abstract}

Keywords: cultural access, reflexivity, agency, subnational culture

\section{Introduction}

The discourse on access and adoption of Information and Communication Technologies (ICTS) and technological networks in Africa is often constructed unproblematically using digital divide arguments. Some studies on disparities in ICT access and adoption have been conducted using empirical approaches (Mutula, 2008; Bagula, Zennaro, Nungu and Nkoloma, 2011; Sedoyeka, 2012) and theoretical perspectives (Fuchs and Horak, 2008; Oludopalo, 2010). Empirical studies have often over relied on International Telecommunications Union's (ITU) technology and connectivity data, content analysis, case studies (Mutula 2008; Bagula, Zennaro, Nungu and Nkoloma, 2011) and surveys on the level of technology adoption (Sedoyeka, 2012) to make sense of the extent of the digital divide in individual African countries. These accounts often emphasise a skewed distribution of the Internet, electronic networks and communication, content, technological infrastructure as well as the paucity of social amenities in developing world contexts.

Although these in-depth studies provide illuminating reasons for the differential uptake of technologies and the downsides of technological exclusion such as information asymmetries, development lags, and limited political participation in democratic processes, they fall short in several analytical respects: (1) They are rooted in technological determinism) (2) They are premised on diametrically polarised conceptions of technology haves and have-nots, which fail to address the intra-cluster variations in technology access of each group. (3) They are based on a linear development trajectory that glorifies and essentialises technology as the sole driver of development.

With regard to (1), Warschauer (2003) argues that it is clear that the underlying framework of the "digital divide" is technological determinism - that is, the view that the mere presence or absence of a technology has a determining effect 
on human behaviour and social development. With reference to (2), Galperin (2010) argues that one key shortcoming of the [digital divide discourse] is the implicit assumption that all countries would converge on a similar path of ICT infrastructure development and adoption. The discourse assumes that technological binaries between countries can be breached through resource poor countries' unproblematized imitation of the development trajectories of developed economies. In relation to (3), Mutula (2008) contends that sub-Saharan African countries lag behind other world nations and need to catch up with the developed world with regard to digital literacy, availability of relevant content, affordability of access, quality of networks, universal access and universal service. The phraseology of this discourse such as "catching up" and "lagging behind" is symptomatic of some adherence to a linear, deterministic, development philosophy that neutralises human agency inadvertently in this developmental equation.

Having questioned the digital divide arguments about the polarity of access to technologies and learning resources in Africa, this paper argues that students access to learning resources lies on a continuum involving variations in meaningful access based on an assortment of individual, contextual and broader socio-technological considerations. As such, the goal of this paper is twofold:

1. To explore the extent of access to different institutionally-sanctioned educational technologies and resources of Computer Science and Informatics students at a South African university; and

2. To explore the different ways in which these students construct agency through their innovative and strategic access to existing educational resources and other emerging technologies.

\subsection{Student agency in resource constrained contexts}

Since this paper is also preoccupied with student construction of agency through productive use of educational resources, the term agency necessitates a definition. Giddens (1976, p. 75) "...define[s] action or agency as the stream of actual or contemplated causal interventions of corporeal beings in the on-going process of events-in-the-world". Embodied in his definition is the continual negotiation of individual actions (actual/ anticipated) and strategies within a limited set of alternatives/scenarios in a complex world of human interactions. Similarly, Martin (2004, p. 135) characterises agency as "the capability of individual human beings to make choices and to act on these choices in a way that makes a difference in their lives". While choices / decision making and strategy are critical to enacting agency, they do not unfold at the whims of the agent (student). Rather they are context informed and bound by both enablements and constraints. Acknowledging this limitation, we identify with Martin's (2004) conception of agency.

\section{Literature Review}

\subsection{The digital divide}

The digital divide has often been used to grasp the level of ICT access, adoption and appropriation by continents, nations, institutions and individuals. However, the concept is plagued by a definitional crass owing to the multiple interpretations of the term (Sciadas, 2002; Wolff and MacKinnon, 2002; Oludopalo, 2010). For instance, literature describes the digital divide as "inequalities in access to and utilisation of information and communication technologies" (ICTs) (Wolff and MacKinnon, 2002, p.7) due to the unavailability of ICT facilities or prohibitive cost of acquiring them (Oludopalo, 2010). Although an additional dimension of effective use is added to the description of access, this definition lacks specificity about the technologies involved. Sciadas (2002) observes that the digital divide depends on specific technologies, their timing of introduction, and variables of interest involved. For example, ICT penetration rates grow with income, with the effect of income becoming larger on newer ICTs (Internet, computers and cell phones) than older and established ones (television and telephone) (Sciadis, 2002).

\subsection{Technology access in South African educational contexts}

The South African higher education (SAHE) terrain is inexorably complex to characterise with precision due to the differentiation of ICT policies and programmes at individual universities as well as the diversity of ICT infrastructure and preferred technologies at these institutions. While a majority of South African universities use dedicated institutional learning management systems (LMSs) for content management and delivery, variations persist in the implementation of ICT delivery programmes and use of collaborative technologies to support pedagogical delivery

Farrell, Glen and Isaacs (2007) articulate the complexity of ICT adoption and implementation at South African universities. On one hand, they commend South African universities for developing policies that articulate the manner in 
which ICTs are integrated into teaching and learning processes. On the other hand, they also acknowledge that, albeit access to high speed connectivity, limited technological infrastructure, a lack of access to infrastructure, affordable and sufficient bandwidth, and the human resource capacity to exploit the technology continue to limit the productive application of technologies in higher education. For instance, Bosch (2009) observes that although Vula [the University of Cape Town's (UCT) local brand of Sakai-based learning management system (LMS)] remains the main gateway for student access to course-related materials, its collaborative tools have been sub-optimally accessed and adopted for learning. A survey conducted by Ng'ambi, Gachago, Ivala, Bozalek and Watters (2012) on 262 SA university educators' use of technologies reports on the dominance of LMSs or content management systems (CMS) as content repositories and transmission portals used by educators. This is not withstanding the popularity of other Web 2.0 technologies such as research databases (75\%), social media (69\%), e-books (67\%), social networking (64\%), web-based documents (63\%) and Open Educational Resources (OER) (60\%).

Czerniewicz, Ravjee, and Mlitwa (2006) affirm that access to ICTs has the potential to increase access to higher education, reconfigure libraries and institutional management as well as improve the quality of teaching and learning. Mlitwa (2005) demonstrates how the University of Western Cape's e-Learning Strategy Draft of 2004 strives to (1) broaden physical availability to ICTs through $24 / 7$ access to computers, increase student to computer density and improve equality of access to information; (2) Ensure usability of content and applications through integration of ICTs into pedagogy, opening up open content tradition and linking the LMS to other online systems; and (3) Build users' capabilities (literacies) through basic computer literacy, digital information and fluency. The challenge, however, is to translate these ideal policy documents into practical interventions for promoting effective access to and pragmatic application of ICTs.

\subsection{Theoretical framework: Archer's theory of reflexive agency}

A sufficient understanding of effective access to ICTs in resource-poor contexts invokes student agency. Archer (2007a, p. 4) defines reflexivity as "the regular exercise of the mental ability, shared by all normal people, to consider themselves in relation to their (social) contexts and vice versa". This means that the course of actions that cogent beings take are not arbitrary, but are consequences of their careful evaluations of themselves (identity), their abilities and anticipated consequences against the social circumstances that they find themselves in. Reflexive deliberation captures human agents' evaluations of their situations in the light of their personal concerns and their re-evaluation of their projects in the light of their situations (Archer, 2010a). Students, therefore, are not necessarily captive audiences of their social circumstances of varied ICT access but rather exert their agency through negotiating with their social conditions and capitalising on the enablers of the social environment to reproduce or transform it.

Margret Archer's theory of reflexive agency endorses agency that is embodied in reflexivity operating at both individual level through internal dialogue (autonomous reflexivity) and at collective level through dialogic conversations (communicative reflexivity). Autonomous reflexivity involves lonely internal conversations that are carried out with a performative aim and result in changes in social structure (i.e. structural discontinuities) (Archer, 2003; de Vaujany, 2008). On the contrary, communicative reflexivity involves an open internal dialogue carried out in thought processes and conversations recursively by an agent, which serves to reproduce existing social structures (Archer, 2003; 2010a). The discursive deliberations and choices that students engage in are constitutive of different reflexivity - some internal conversations aimed at the transformation of social structures (broader contexts) and others collective dialogues geared at mediating continuity in the social context.

Meta-reflexivity describes the lonely internal conversation about one's internal conversations that lead to further refinement of thoughts (Archer, 2003; de Vaujany, 2008). It involves "stepping back from full engagement in cultural activity", itself a "form of ironic detachment: a disengagement from tribal custom and a heightened awareness of takenfor-granted assumptions" (Lynch, 2000: 30). Such an internal process of critical questioning challenges conventional thinking and triggers new thoughts that result in self-realisation. Drawing on the work of Archer (2003), de Vaujany (2008) conceives fractured reflexivity as a reflexive process that only works to a certain point, after which internal conversations and concerns (intentions) can no longer be correlated. For instance, a change in the sociocultural context may complicate the ability of the reflexive agent to draw on the conditioning context, thus making the reflexive process ineffective.

In view of the foregoing discussion, the analysis of findings of this study will be informed by the four forms of reflexivity as illustrated in Table 1. 
Table 1: Archer's typology of reflexivity

\begin{tabular}{ll}
\hline \multicolumn{1}{c}{ Category } & \multicolumn{1}{c}{ Description } \\
\hline $\begin{array}{l}\text { Communicative } \\
\text { reflexivity }\end{array}$ & $\begin{array}{l}\text { Internal conversations need to be confirmed and completed by others before they lead to action, thus } \\
\text { fostering normative conventionalism. }\end{array}$ \\
$\begin{array}{l}\text { Internal conversations are self-contained, leading directly to action and are characterised by } \\
\text { reflexivity }\end{array}$ & $\begin{array}{l}\text { instrumental rationality. } \\
\text { Internal conversations critically evaluate previous inner dialogues and are critical about effective } \\
\text { Meta-reflexivity }\end{array}$ \\
$\begin{array}{l}\text { action in society, in promoting value rational action. } \\
\text { Internal conversations cannot lead to purposeful courses of action and only intensify personal } \\
\text { distress and disorientation, leading (temporarily) to 'passive agents'. }\end{array}$ \\
\hline
\end{tabular}

Source: Archer, 2010a: 9

\section{Methodology}

This study used a survey approach to investigate the extent of student access to various learning resources in the computer labs at the institution that was researched. Cohen, Manion and Morrison (2007) consider surveys appropriate when the intention is to gather large scale data from a representative sample population to ascertain with a measure of statistical confidence that certain observed characteristics occur with a large degree of regularity or [...] cluster together (p. 206). Since the intention was to acquire standardised information on the extent of student access (by gender, residential location) to educational technologies including their ownership of mobile devices (by first language spoken - a viable proxy of race), surveys were deemed as most appropriate for this investigation. Students were invited to log on to a website and complete an in-depth semi-structured questionnaire. A total of 109 Computer Science and Informatics (CSI) students from three levels of study (first year to third year) participated in the study of which 100 students successfully completed the survey. Upon the completion of the survey, all the responses were loaded into statistical package for the social sciences (SPSS) for the analysis of data. The results were put in conversation with Archer's (2010a) framework (see Table 1) to interpret the meaning in their situated contexts of SAHE.

The subsequent section of the paper describes the population sample by gender, age, level of study and residential status.

\subsection{Demographic data}

The majority (68.8\%) of respondents who completed the survey were males (with $31.2 \%$ females). This gender distribution reflects enrolment patterns of the CSI department, in which the male students are more dominant than their female counterparts.

A large number of the respondents were aged between 20 and 21 years (42.2\%) followed by the 22 to 23 age group (24.8\%) and the 18 to 19 years (20.2\%). The rest of the students (12.8\%) were above 24 years of age. This age distribution was anticipated since the survey respondents were predominately undergraduate students.

As expected, the majority of CSI respondents were in their first year of study (55.0\%), a third (32.1\%) of the respondents were in their second year of study and the rest $(12.9 \%)$ were in their third year of study. In terms of residential status, a majority (75.2\%) of the students were off campus while the remainder (24.8\%) were on campus.

\section{Findings and Discussion}

\subsection{Gender asymmetry in enrolments}

The majority (68.8\%) of respondents who completed the survey were males (with $31.2 \%$ females). These statistics seem to reflect the general student enrolment figures of the CSI Department and of the Science, Engineering and Technology (SET) disciplines at this institution. They potentially suggest the constraining effects of the broader societal structures on female participation in Natural Science subjects. These structures include the limited prior socialisation and career guidance of females to participate in SET subjects at high schools and patriarchy that reinforce the belief that "difficult" technical subjects are the domain of males. To this end, the aforementioned gender asymmetry might have moulded female students to function in the "fractured reflexivity" (Archer, 2010a) mode. Fractured reflexives usually have no real projects (courses of action) as their internal deliberations do not allow them to deal successfully with their situations, 
making them passive agents who are at the mercy of their social environment (Archer, 2003). In the same vein, female students' minority status potentially undermined their capacity to identify with their male counterparts as competent equals in their discipline. Behavioural psychology highlights that the actions and conduct of the dominant outward group tend to influence and shape the in-group behaviour of minority group through social conditioning, peer influence and group dominance.

\subsection{Use of computer labs to access services and resources}

As anticipated, student use of the institution's computer labs for accessing various learning resources was quite phenomenal, notwithstanding the variations based on student gender. A logical hierarchy of lab access emerged: Access to the institutional LMS ranked highest (95\%), followed by browsing the Internet (90\%) and online tutorials (88\%) (See Table 2). The predominant use of computer labs for academic oriented activities presupposes students' exercise of autonomous reflexivity. Since an autonomous reflexive completes her own internal conversation in relative isolation from the concerns of others (Mutch, 2007:1129) it can be inferred that students constituted conscientious agents seeking to optimise their individual concerns (academic goals) in light of their structural constraints. For instance, given that a majority of students were off campus learners whose access to internet resources outside campus was limited, their intensive use of labs for academic activities suggests their deliberative (discursive) consciousness about asymmetrical access to networked resources.

The high uptake of the LMS might also be reflective of CSI educators' commitment to become trailblazers of blended learning at the institution, which involves online delivery of some components of teaching and learning materials. As communicative reflexives who engage in internal conversations that need to be completed and confirmed by others (peers) before they lead to action (Archer, 2010a), it can be anticipated that their collective action served to reinforce social structure (the image of early adopters of technologies).

Overall, the commendable use of the Internet buttresses Mahmood's (2009) view that ICT use by students has expanded to Internet browsing, online literature searching, e-mail and relay chats. The encouraging statistics help project students as active agents who conceived computer labs as their first-port-of-call for accessing educational resources.

Table 2: Use of the computer labs to access services and resources $(n=100)$

\begin{tabular}{lccccc}
\hline Access to a service or resource & $\begin{array}{c}(\mathbf{1}) \\
\text { Never }\end{array}$ & $\begin{array}{c}(\mathbf{2}) \\
\text { Small } \\
\text { degree }\end{array}$ & $\begin{array}{c}(3) \\
\text { Moderate } \\
\text { degree }\end{array}$ & $\begin{array}{c}\text { Large } \\
\text { degree }\end{array}$ & $\begin{array}{c}\text { Average Rating out } \\
\text { of } 4\end{array}$ \\
\hline To access the Blackboard LMS & $5 \%$ & $20 \%$ & $13 \%$ & $62 \%$ & 3.32 \\
To access printing services & $34 \%$ & $26 \%$ & $20 \%$ & $20 \%$ & 2.26 \\
To browse the Internet & $10 \%$ & $23 \%$ & $15 \%$ & $52 \%$ & 3.09 \\
To access social networking sites (such as Facebook, & $30 \%$ & $26 \%$ & $28 \%$ & $16 \%$ & 2.30 \\
MySpace, MXit, Twitter) & $77 \%$ & $16 \%$ & $4.0 \%$ & $3 \%$ & 1.33 \\
To play online games & $12 \%$ & $22 \%$ & $27 \%$ & $39 \%$ & 2.93 \\
To access online tutorials & & & & & \\
\hline
\end{tabular}

The dominance of academic-related uses of lab computers is symptomatic of student reflexive monitoring of their activities and tasks to ensure successful accomplishment of learning tasks (personal agency). This perfectly resonates with Archer' (2010a) autonomous reflexivity, in which an individual student's internal dialogues in light of the given constraining academic circumstances (lack of internet access at home, lack of web-enabled phones, erratic connectivity) become a motivation for her engagement in purposeful courses of action like on-task behaviour and effective time management in labs. For Archer (2010a) deliberation of autonomous reflexivity consists of people evaluating their situations in the light of their concerns and evaluating their projects in the light of their circumstances.

As such, these students' personal commitments to execute assigned tasks interplayed with prevailing social circumstances (pressure to meet online submission deadlines, pressure to access free work stations and "free" Internet) that shaped their academic conduct in labs. These collisions between personal intentions (embodied in internal dialogue) and social structure (limiting their agency) resulted in the "self-monitoring" of their activities to ensure academic progress. Off campus students with limited access to laptops and Internet networks after-hours concentrated strategically on electronic and network-mediated tasks (quizzes, assignments, test writing and submissions) in labs and accomplished complementary activities (reading, discussions) at home. This resonates with South African university students' complex technological "habitus," which functions within a paucity of access and limited practices in relation to computers, in contexts where computers and their associated practices are highly valued (Czerniewicz and Brown, 2013). 
Access to social networking sites (SNS) was among the least ranked services in spite of the availability of standalone computers in the labs (see Table 2). Although 54\% of the participants relatively accessed SNS via computer labs, only $16 \%$ of them reported considerable access. The fact that the remainder (30\%) of students surveyed had never accessed SNS via these labs could be indicative of students' uptake of alternative technologies like mobile social media, in contexts where social networking was discouraged by educators and lab administrators. Their incapacitated condition in labs constitutes fractured reflexivity, comprising the temporary decapitation of the exercise of individual agency. Fractured reflexives cannot conduct purposeful internal conversations and thus design (alternative) purposeful courses of action (Archer, n.d.). They are never able to achieve their personal projects and remain 'primary agents', that is, with their life chances determined to a significant degree by their involuntary positioning (Mutch, 2007, p. 1129, Archer, 2003). The utilisation of mobiles outside the labs is plausible given the $71.1 \%$ and $55.7 \%$ ownership of smart phones and low end cell phones reported among CSI participants respectively.

Participants' choice of cell phones to access SNS albeit the availability of institutionally-sanctioned networks demonstrates that they strategically adopted specific technologies at different spatial and temporal times to meet their learning and social needs. This view buttresses Czerniewicz and Brown's (2013, p. 52) finding that students "use what they have and what they can to gain entry into a [research] field [and] to consciously engage with the m-learning opportunities available within all educational contexts faced with social and digital inequalities." In our case, students agency played out in students sourcing their "own" technologies to complement, supplement or even supplant those availed by the institution.

The majority of participants (77\%) had never used the computer labs to access online games. Given that online gaming is not yet an established educational practice at SAHE institutions, it is not surprising that many students had never participated in online gaming in labs. This demonstrates fractured reflexivity-where internal conversations cannot lead to purposeful courses of action and only intensify personal distress and disorientation, leading (temporarily) to 'passive agents' (Archer, 2010a). Fractured reflexives have their powers of reflexivity either temporarily suspended as they are moving from one mode of reflexivity to another or even impeded all together by their structural conditions, resulting in cognitive disorientation (Archer, 2003). Perhaps this inability to deal with their social conditions (productive use of games) is a consequence of educators' construction of online games not as an authentic, cognitively intensive learning activity. Ng'ambi, Gachago, Ivala, Bozalek, \& Watters (2012) confirm that few South African university educators have used online games regularly for pedagogical purposes.

\subsection{Access to different learning resources in labs by students' gender, level of study and residential status}

\subsubsection{Access to LMS by gender}

The disaggregation of data on access to learning resources in labs (see Table 2) by gender provided interesting dimensions about institutional access, which seemed to confirm the CSI enrolment figures by gender. A marginally higher percentage $(76.81 \%)$ of male students accessed LMS resources via the labs compared to females $(70.97 \%)$. This gender asymmetry is however inconsequential since the percentage difference is small. This suggests both genders' agency with regard to the use of available educational resources within their circumstances and contexts. In spite of their minority status, however, female students were as actively involved in academic activities as their male counterparts suggesting a balanced relational agency across both genders. Female students' agency in the face of constraining social structure (departmental enrolment policy) constitutes meta-reflexivity. This meta-reflexivity (reflecting on one's reflections) allowed them to question established gender asymmetries and resort to their mental faculties for academic survival. Archer (2010b: 299) reports that micro contextual discontinuity stemming from interpersonal disharmony [caused by skewed gender enrolments], may deprive meta reflexives of continuous, trusted interlocutors, thus throwing them back upon their own mental resources.

\subsubsection{Access to LMS in computer labs by student levels of study}

When student access to LMS in labs was considered in conjunction with their year of study, second years dominated inlab access compared to their counterparts. While almost universal access (90.63\%) was recorded among second years, this could not be said of the other cohorts (first years $\{70.17 \%\}$; third years $\{54.55 \%\}$ ). These variations might be a consequence of several factors such as the frequency of lab tasks (quizzes, tests and assignments), extent of Webbased research involved and peer-based evaluation required at each academic level. Since the second year often constitutes the consolidation phase of three year degrees of study (after the first foundational phase), the higher access 
to LMS in labs at this level is potentially conceivable. If the nature of the course is conceived as one of the broader structure upon which students agency (access and use of LMS in labs) is tied, then agency "tends to remain so tightly bound to structure that one loses sight of the different ways in which agency actually shapes social action" (Emirbayer and Mische, 1998, p. 963). The second years' higher involvement with LMS can be interpreted as a form of fractured reflectivity imposed by the high demands of the course rather than an expression of personal initiative per se.

\subsubsection{Access to LMS in computer labs by student residential status}

While student residential status provided some aggregated data on the dispersion of students in relation to contact-based educational resources, it failed to provide some insights into individual variations in access to particular kinds of networked resources. Data was disaggregated to capture the extent of student access to individual resources in the labs based on their residential status. Surprisingly, off campus students generally enjoyed more access $(77.03 \%)$ to the institutional LMS in the labs compared to their on campus counterparts (69.23\%). This interesting dynamic of access suggests that students with limited access to lab resources after hours due to geographical remoteness were more strategic and tactical in their extent and frequency of access to compensate for their asymmetrical access after-hours. This demonstrates that off campus students served as autonomous reflexives in constrained contexts of limited resources. As very productive workers, autonomous reflexives are preoccupied with work commitments and continually adjust their life projects as they re-revaluate their concerns in changing contexts (Sanghera, 2009:5). The higher use of LMS by off campus students demonstrates their reflective monitoring of their on-task academic activities consistent with the opportunities (enablers) and constraints (such as gradations of access to lab resources) that the learning environment provided.

\subsubsection{Access to printing services by gender}

While access to printing services in labs was generally low for both genders, female access (45.16\%) was significantly higher than that of males (37.68\%). Female students' higher access to printing services potentially signifies their enactment of agency with regard to the productive use of available printing services. Agency, captures "the capability of individual human beings to make choices and to act on these choices in a way that makes a difference in their lives" (Martin, 2004, p. 135) within the context of conditioning social circumstances. These slight variations in access demonstrate different autonomous reflexivity expressed in females' greater commitment to put existing ICT resources to desirable use than their counterparts. Autonomous reflexives demonstrate agency by pragmatically positioning themselves through strategic grasping of opportunities, engaging in self performative acts geared at promoting selfimprovement and circumventing obstacles (Shanghera, 2009:5). Productive use of available resources therefore demonstrates the practical reflexivity aimed at self-development and advancing academic mobility.

However, the generally low student access to printing services in computer labs is potentially explained by a combination of factors: , 1) Use of personal printers, 2) Printing in nearby business centres due to the congestion of walkin labs, 3) Educators' requirements for online submissions, which made the submission of hard copies unnecessary. These diverse courses of actions like the search for alternative printing facilities or avoiding printing in labs signify that while the structure-agency dichotomy embodies mutually constitutive elements (agency, interaction and structures), these individual elements are distinct and not reducible to one another. Humans "shape it [i.e. structure], whilst it re-shapes [them] as [they] go about changing it or maintaining it, individually and collectively" (Archer, 2007b, p. 38). Options 1 to 2 denote student agency's reconstitutions of structure, while 3 suggests a facilitating condition (enablement) generated from structure. Option 1 and 2 fit both the autonomous reflexivity and communicative reflexivity while 3 constitutes fractured reflexivity to the extent that it a directive of a facilitative nature. From a communicative reflexivity perspective, individual student internal dialogues about challenges of printing in crowded spaces may trigger collective actions about the avoidance of these institutionally provided spaces (in-group behaviour by CSI students). For Archer (2010b, p. 299) communicative reflexives come from stable and geo-local backgrounds, where interpersonal relations are warm, convivial, and lasting, friendship networks are richly rewarding. These forms of cultural capital activate transactive expressions of agency through shared perspectives, conciliatory behaviour and group decision making with regard to the valuing and appropriation of learning resources.

\subsubsection{Access to printing services in the lab by levels of study}

Although access to printing services was generally low across the different levels of study, second years relatively 
accessed the labs more (56.26\%) for printing services than their counterparts (first years $\{35.08 \%\}$; third years $\{18.18 \%\}$ ). Since the volume of work and mode / format of assignment submissions (hard copies/online submissions) could have influenced the frequency of access to labs for printing services, the consolidation phase of study might have generally required more printing of readings and submissions than other phases. Therefore, it is important to understand that student agency, does not function ad finitum (continually in the same way) but is rather mediated by different contexts that shape and inform their different courses of action. For Archer (2010: 226) although social structure shapes human interactions [but in a non-determinist way], 'action' and 'structure' presuppose one another: structural patterning [that] is inextricably grounded in practical interaction.

\subsubsection{Access to printing services by residential status}

Overall, $58.11 \%$ of on campus students accessed printing services in the labs compared to $88.46 \%$ of off campus students. This higher involvement of off campus students in printing notwithstanding their limited access to labs afterhours suggests their exercise of autonomous reflexivity in the face of constraining circumstances. For Lindgren and McDaniel (2012), agency and choice do not unfold out of context but rather can be elicited generally through student interaction with the situated environments in which they operate. As such, when students are confronted with constraints of access, they strategically enlist resources in spatial and temporal contexts to compensate for their lack of access elsewhere.

\subsubsection{Access to Internet browsing by gender}

There was no significant statistical difference (2.19\%) between female and male participants with regard to access to internet browsing in computer labs. Given that much of university assignments demanded extensive use of the Internet, a gender balance in terms of access was anticipated. Mindful of the 24/7 access to lab facilities at this university, the fairly high access (females $\{64.52 \%\}$, males $\{67.71\}$ ) was logical, although universal access to these services after hours was inconceivable due to differences in student residential status. The relative gender balance, however, suggests individual student commitment to strategically draw on and appropriate institutionally sanctioned resources in the completion of academic tasks and in pursuit of meaningful academic participation. This equitable exploitation of available resources by both genders suggests the enactment of agency by communicative reflexives. Communicative reflexives normally settle for contextual security and ensuring that their concerns and the prevailing context are properly aligned (Sanghera, 2009:4). They tend to be content with their context and display some adaptation to their contexts of engagement.

\subsubsection{Access to internet browsing in computer labs by level of study}

All the different cohorts had high access (first years $\{56.14 \%\}$; second year $\{87.51 \%\}$; third year $\{63.64 \%\}$ to the Internet via the labs. Second years had significantly higher scores. The generally higher levels of internet access are accoutrements of the core enterprise of the university-expectations for information search, knowledge construction and negotiation. Mindful of the dominance of first years in our sample, their comparatively lower levels of Internet is surprising. It might, perhaps be attributed to the surface approaches to learning at that level, where students often over rely on lecture materials for their assignments. This characterisation resonates with fractured reflexivity, involving the recession of reflexive monitoring leading to distress and disorientation (Archer, 2007) due to their difficult encounter with complex scholarship, shifting academic contexts and the collapse of routine intellectual activity. The aforementioned findings on surface learning and fractured reflexivity resonate with Baxter-Magolda's (1992) findings about the dominance of absolute knowing among first year students.

\subsubsection{Access to internet browsing in labs by student residential status}

Access to Internet browsing via computer labs reflected a trend similar to that of access to LMS. Generally, off campus students' access to Internet browsing was marginally higher (68.91\%) than on-campus students' (61.53\%). Several reasons could account for this surprising revelation. It could be indicative of off-campus students' additional effort and dedication to accessing labs during the day because of their differentiated and asymmetrical access to learning resources after hours. It is common practice that under-resourced students with limited access to computer networks often rely on strategies like investing much time in downloading materials and reading offline ( $\mathrm{Ng}$ 'ambi and Rambe, 2008) to overcome their digital exclusion. Such practices fit within Archer's (2010a) meta-reflexivity category where student internal dialogues 
are critical of effective action in the face of structural constraints and consequently trigger rational action.

\subsubsection{Access to social networking sites in computer labs by gender}

Although student access to social networking sites in labs was generally lower for both gender ( less than 50\%), male students' access was generally higher (47.82\%) than that of females (35.48\%). Male students' higher access to social networking sites in labs could be attributed to their preference for multi-tasking, involving the interfacing of intermittent social networking with on-task activities. In stressful academic situations, the Net generation's incorporation of relaxation into their demanding work schedules can be interpreted as a copying mechanism and survival strategy-itself an expression of autonomous reflexivity. As such, Archer's (2003) agential reflectivity emphasises [psychological] mediation through enablement and constraints, one in which a given course of action can be consistently sustained across different social contexts.

\subsubsection{Access to social networking sites by level of study}

First year students had relatively higher level of lab-based access to social networking sites (64.91\%) compared to second years (28.13\%) and third years (36.36\%). The fact that social networking sites are often associated with playful, informal learning and that some university educators conceive students' social networking activities to be devoid of intellectual substance further reinforce more mature students' limited use of them. Since students move from superficial learning towards deep and procedural learning in their progression in university education (Magolda, 1992), second and third years' university engagement were bound to reflect more agency in their strategic use of conceivably flippant and distractive educational software.

\subsubsection{Access to online video games in computer labs by gender}

Although access to online video games was considerably low for both gender (females $\{6.46 \%\}$; males $\{7.25 \%\}$ ), there was a marginal statistical difference between them. The limited use of labs for the playing of video games suggests the availability of alternative technologies (such as mobile phones, PDAs, laptops) from which students played / watched them in addition to standalone PCs. As such, students enacted agency by choosing the location, time, circumstance and specific technology to appropriate for watching them, which presented multiple possibilities. As such, the individual student is not a captive audience of social reality and structure, but rather "has powers of on-going reflexive monitoring of both self and society (Archer, 2002, p. 19). Autonomous reflexivity, therefore, enables and affords individual students the enactment of the empowering force to act within or to transcend social contexts in their actions (self-monitoring of reflexivity).

Alternatively, the limited appropriation of these technologies could also be reflective of lab assistants' monitoring of student use of computers for academic tasks exclusively (vertical monitoring and / peer monitoring). These gatekeeping practices and controls would have worked to sediment "fractured reflexivity" (Archer, 2010a), in which student selfmonitoring in response to vertical monitoring by lab personnel reinforced the identity of complying, "passive" subjects.

\subsubsection{Access to online tutorials in computer labs by gender}

Notwithstanding the high use of computer labs by both gender (females $\{70.97 \%\}$; males $\{63.77 \%\}$ ) significant differences persisted between them. These differences could be attributed to different work styles between females and males, with the latter preferring procrastination and perhaps working under pressure than their female counterparts. The different work practices and ethics could be symptomatic of different forms of reflexive action at work, based on their assumed/ potential/ actual capabilities.

\subsubsection{Access to online tutorials in the labs by level of study}

Just like internet access in the labs, access to online tutorials in the labs was dominated by first (68.42\%) and second years (68.76\%). While it is difficult to attribute this to any student traits, their dominance can only be interpreted as a consequence of the varying numbers of online tutorials specific to individual cohorts' or levels of study. 


\subsubsection{Access to online learning tutorials in the labs by residential status}

Online access to tutorials was relatively balanced between students irrespective of their residential location (off-campus students $\{66.22 \%\}$; on-campus $\{65.38 \%\})$. Since all students were expected to conduct online tutorials as part of their academic work, this balanced representation could be indicative of this requirement. This finding contradicts Mahmood's (2009) claim that students mostly use ICT for general purposes, i.e., communication, word processing, entertainment, etc. rather than for educational purposes and even students of professional subjects do not use ICT excessively for accessing educational materials.

\subsection{Implications for pedagogy}

The following section summarises the main findings and their implications for pedagogy as follows:

- There was limited female participation in the CSI discipline across all academic levels judging from the low enrolment of females. Therefore, some structural interventions for the socialisation of female students to SEM disciplines should be established early in their academic careers (e.g. high school) to foster female student interest and adequately prepare them for science disciplines.

- Access to emerging technologies such as SNS and online video games was disappointingly low. Concerted efforts to investigate students' sub-optimal access and use of emerging technologies for educational purposes are necessary. Educators should explore this skewed access to new technologies to ensure multiple access to educational resources and deepen productive pedagogical use of these technologies.

- The gender gaps in student use of SNS means that educators need to explore and provide best exemplars of productive educational appropriation of these sites. Since the use of SNS in labs is contested, such examples should be trialed in classrooms before their demonstration in labs.

- The reasons for second years' comparatively higher usage of LMS, online printing services and internet browsing need to be explored and then pragmatically rolled out to other cohorts to support optimal access and use of lab resources. Similarly, why off-campus students enjoyed higher access to lab facilities than their oncampus counterparts needs exploration to ensure equitable use of institutionally-sanctioned networks.

\section{Conclusion}

The study challenged traditional notions of the digital divide that entrench polarisation of access and replaced them with gradations and variations in access to different education resources. Archer's theory of reflexivity was drawn upon to investigate student extent of access to educational resources and services mindful of their different academic circumstances (e.g. gender imbalances in CSI enrolments) and situated learning contexts (e.g. students' varied residential status). As such, different forms of reflexivity were then drawn upon to interpret how these differentiallypositioned (in terms of place, time, temporal zones and gender) students appropriated, enacted, reproduced and sustained their agency through their varying access to learning resources and technologies in labs.

The findings suggest that while social structure and forms of agency (autonomous reflexivity, communicative reflexivity, and fractured reflexivity) co-constituted and evolved with one another they also remained distinct from one another. At times and in particular contexts one form of reflexivity was activated and in other circumstances a collective of reflexivities were enacted and reinforced each other. At best, student access to computer lab facilities and services were dominated by traditional forms of access to LMS, internet browsing and online tutorials and the under-utilisation of SNS and video games. Surprisingly, off-campus students reported a comparatively higher level of access to the majority of educational resources and technologies availed in the labs notwithstanding their limited access to labs after hours. This phenomenon suggests off-campus students' higher level of academic agency embodied in their strategic and pragmatic use of institutionally-sanctioned technologies and other available technologies in different contexts in pursuit of their academic goals.

In spite of the lower female enrolments in the CSI department, female students comparatively fared better than their male counterparts in their use of lab services and resources. This potentially signifies the interplay of individual agency and a novel work ethic in a highly demanding academic environment plagued by access constraints. Finally, the study recommended a further exploration of under-utilised services like SNS, video games and printing services to ensure equitable, balanced exploitation of institutionally-provided resources. 


\section{References}

Archer, (n.d.). The reflexive imperative and social change. Ecole Polytechnique Fédérale de Lausanne Switzerland www.Ise.ac.uk/europeanInstitute/research/...Change/Archer_ppt.pdf

Archer, M. (2010a). Reflexivity. Sociopedia, 1-13.

Archer, M. (2010b). Routine, Reflexivity, and Realism. Sociological Theory, 28(3), 272-303.

Archer M. (2007a). Making our Way through the World: Human Reflexivity and Social Mobility. Cambridge: Cambridge University Press.

Archer, M. (2007b). The trajectory of the morphogenetic approach: An account in the first-person. Sociologia, Problemas e práticas, 54, 35-47.

Archer, M. (2003). Structure, Agency and the Internal Conversation. Cambridge: Cambridge University Press.

Archer M. (2002a). Realism and the problem of agency. Journal of Critical Realism, 5, 11-20.

Archer M. (2002b). Realism and the problem of agency. Journal of Critical Realism, 5, 11-20.

Bagula, A., Zennaro, M., Nungu, A. and Nkoloma, M. (2011). Bridging the Digital Divide in Africa: A Technology Perspective. Wireless Communication and Information, 7-28.

Baxter-Magolda, M. (1992). Knowing and reasoning in college: Gender-related patterns in students' intellectual development. San Francisco: Jossey-Bass.

Bosch, T. (2009): Using online social networking for teaching and learning: Facebook use at the University of Cape Town. Communicatio: South African Journal for Communication Theory and Research, 35(2), 185-200.

Cohen, L., Manion, L., and Morrison, K. (2007). Research methods in education. New York, NY: Routledge.

Czerniewicz, L. and Brown, C. (2013). The habitus of digital "strangers" in higher education. British Journal of Educational Technology, 44(1), 44-53.

Czerniewicz, L., Ravjee, N. and Mlitwa, N. (2006). Information and Communication Technologies and South African Higher Education: Mapping the landscape. Research Report for the Council on Higher Education, Council on Higher Education, Pretoria.

De Vaujany FX. (2008). Capturing reflexivity modes in IS: a critical realist approach. Information and Organization, 18(1), 51-72.

Emirbayer, M. and Mische, A. (1998). What Is Agency? Reviewed work(s): American Journal of Sociology, 103(4), 962-1023.

Farrell, G. and Isaacs, S. (2007). Survey of ICT and Education in Africa: A Summary Report, Based on 53 Country Surveys. The International Bank for Reconstruction and Development, Washington, DC: infoDev / World Bank. Available at http://www.infodev.org/en/Publication.353.html

Fuchs, C. and Horak, E. (2008). Africa and the digital divide, Telematics and Informatics, $25,99-116$.

Galperin, H. (2010). Goodbye Digital Divide, Hello Digital Confusion? A Critical Embrace of the Emerging ICT4D Consensus. Information Technologies \& International Development, 6, $53-55$.

Giddens, A. (1976). New rules of sociological method. London: Hutchinson.

Ivala, E. and Gachago, D. (2012). Social media for enhancing student engagement: The use of Facebook and blogs at a University of Technology, South African Journal of Higher Education, 26(1), 152-167.

Mahmood, K. (2009). Gender, subject and degree differences in university students' access, use and attitudes toward information and communication technology (ICT), International Journal of Education and Development using Information and Communication Technology , 5(3), 206-216.

Lynch, M. (2000). Against Reflexivity as an Academic Virtue and Source of Privileged Knowledge, Theory, Culture \& Society, 17(3), 2654.

Lindgren, R., \& McDaniel, R. (2012). Transforming Online Learning through Narrative and Student Agency. Educational Technology \& Society, 15 (4), 344-355.

Martin, J. (2004). Self-Regulated Learning, Social Cognitive Theory, and Agency. Educational Psychologist, 39(2), 135-145.

Mlitwa, N. (2005). Higher Education and ICT in the Information Society. A case of UWC. CIRN 2005 Conference (pp. 1-21). Cape Town, 22-31 August 2005.

Mutch, A. (2007). Reflexivity and the Institutional Entrepreneur: A Historical Exploration. Organization Studies, 28, 1123-1140.

Mutula, S. (2008). Digital divide and economic development: case study of sub-Saharan Africa. Electronic Library, 26 (4), $468-489$.

Ng'ambi, D., Gachago, D., Ivala, E., Bozalek, V., \& Watters, K. (2012). Emerging Technologies in South African Higher Education Institutions: Towards a Teaching and Learning Practice Framework, Lam, P. (Ed.). Proceedings of the 7th International Conference on eLearning (pp. 354-362), The Chinese University of Hong Kong, Hong Kong, 21-22 June 2012.

Ng'ambi, D. and Rambe, P. 2008. Barriers to students' use of electronic resources during lectures. South African Computer Journal, 42, 47-53.

Oludolapo, O. (2010). Bridging the Digital Divide and the Impact of New Media Technologies on Development in South Africa. In S. Soomro (Ed.), New Achievements in Technology Education and Development (pp. 373-387), Croatia: InTech.

Sanghera, B. (2009). Reflexivity, Class and Ethics: A preliminary analysis of moral judgements and philanthropic acts in the UK. Boston University Sociology Departmental Research Seminar, 1-12.

Sciadas, G. (2002). Unveiling the Digital Divide. Connectedness Series,Statistics Canada, Ottawa, available online at: http://www.statcan.ca/english/research/56F0004MIE/56F0004MIE2002007.pdf

Sedoyeka, E. (2012). Obstacles in bridging the digital divide in Tanzania. International Journal of Computing and ICT Research, 6(1), 60-72.

Warschauer, M. (2003). Dissecting the "Digital Divide": A Case Study in Egypt. The Information Society, 19, 297-304.

Wolff, L. and MacKinnon, S. (2002). TechKnowLogia. Knowledge Enterprise, July - September 2002, 7-9. www.TechKnowLogia.org 